\title{
Grammatical Cohesion in Political Discourse of Vietnamese Newspapers and English Newspapers
}

\author{
Dung Dang \\ Faculty of Linguistics and Literature, Tay Do University, Can Tho City, Viet Nam
}

\begin{abstract}
Cohesive devices are definitely significant in written discourse. This work analyses the patterns of cohesion employed in political discourse. The basic purpose of the study is to investigate the frequency and the ways cohesive devices are exploited in textual creations. The linguistic data are ten Vietnamese editorials and ten English editorials. Halliday and Hasan's (1976) model of cohesion is adopted as the theoretical framework. The result indicates that all four types of grammatical cohesion are employed in both Vietnamese and English editorials. Nonetheless, the frequency of use of these devices is not equal. From the findings, it can be concluded that reference devices are the mostly used with diversification whereas ellipsis devices are employed with an unbalanced frequency in both Vietnamese and English editorials.
\end{abstract}

Keywords: political discourse, grammatical cohesion, editorials

\section{Introduction}

These days, newspapers play an extremely important part in our lives because it is a swift and efficient means of information communication. For this reason, articles should be written with great caution to offer the most impressive and profound news. Definitely, cohesive devices are indispensable for without cohesive devices in a text, there will be no cohesion and coherence (Robert, 2019).

Cohesion and coherence are the two fundamental terms in discourse analysis. Cohesion is the use of language forms to indicate semantic relations between elements in a discourse. Bussmann (1998: 199) claims that cohesion refers to various linguistic means (grammatical, lexical, and phonological) by which sentences 'stick together' and are linked into larger units of paragraphs, or stanzas, or chapters. The two main types of cohesion are grammatical cohesion referring to the structural content, and lexical cohesion referring to the language content of the piece. Coherence is grammatical and semantic interconnectedness between sentences that form a text. According to Van Dijk (1997: 9), coherence is how the meaning of sentences in a discourse hung together. It is the semantic structure, not its formal meaning, which creates coherence. Semantically, a text is said coherent when there is unity of meaning among elements of the texts.

This paper analyses the frequency and the ways grammatical cohesion, as a discourse strategy, are utilized in Vietnamese and English newspapers in the creation of textual bond. For the purpose of the analysis, ten Vietnamese editorials ( The Nhan Dan and Sai Gon Giai Phong newspapers ) and ten English editorials ( The Washington Post and New York Times ) are purposively sampled and Halliday and Hasan's (1976) model of cohesion is adopted as the theoretical framework.

\section{Literature Review}

2.1. Discourse analysis and Political discourse 2.1.1 Discourse analysis

Discourse analysis, also called discourse studies, was developed during the 1970s as an academic field. Discourse analysis is a research method for studying written or spoken language in relation to its social context. According to Linguistic Society of America, discourse analysis is sometimes defined as the analysis of language 'beyond the sentence'. This contrasts with types of analysis more typical of modern linguistics, which are chiefly concerned with the study of grammar, the study of smaller bits of language, such as sounds (phonetics and phonology), parts of words (morphology), meaning (semantics), and the order of words in sentences. One starting point is the following quotation from M. Stubbs' textbook (Stubbs 1983:1), in which discourse analysis is defined as (a) concerned with language use beyond the boundaries of a sentence/utterance, (b) concerned with the interrelationships between language and society and (c) as concerned with the interactive or dialogic properties of everyday communication ( Nordquist, 2020). 


\subsubsection{Political discourse}

In any case, whether struggle or cooperation, "politics cannot be conducted without language" (Chilton and Schäffner 1997, 206). Human interaction to a large extent involves language, and linguistic interaction is embedded in and determined by socio-cultural, historical, ideological, and institutional conditions. In relation to politics, it is obvious that discourse organization and textual structure of a variety of discourse types are greatly affected by the specific political situations and processes. That the analysis of political discourse is relevant for the new cross-discipline of discourse studies hardly needs any further argument. Indeed, most scholars doing political discourse analysis are linguists and discourse analysts (Chilton 1985, 1988; Geis 1987; Wilson 1990; Wodak \& Menz 1990).

\subsection{Grammatical cohesion}

According to Halliday and Hasan (1976: 4), cohesion occurs when the interpretation of some elements in the discourse is dependent on that of another. It concludes that the one element presupposes the other. The element cannot be effectively decoded except by recourse to it. Moreover, the basic concept of it is a semantic one. It refers to relations of meaning that exists within the text. Therefore, when this happens, a relation of cohesion is set up, and the two elements, the presupposing and the presupposed, are thereby integrated into a text. Halliday and Hasan (1976: 39) classify grammatical cohesion into reference, substitution, ellipsis and conjunction.

\subsubsection{Reference}

Halliday and Hasan (1976) state that references are expressions which refer to other words in the text for their interpretation. Reference is potentially cohesive because the thing that serves as the source of the interpretation may itself be an element of text.

Prayudha in his study about Halliday's and Hasan's model claims that the interpretation of reference can be divided into endophora (textual) reference and exophoric (situational) reference (Halliday and Hasan, 1976: 33). When the interpretation of a reference lies within the boundaries of text, it is called endophoric relation. This relation forms cohesive ties within the text. The two kinds of endophoric relations are anaphora and cataphora. Anaphora is the presupposition of something that has gone before, whether in the preceding sentence or not. It is a form of presupposition that refers to some previous item. Cataphora refers to the presupposition in the opposite direction, with the presupposed element following (Halliday and Hasan,1976: 17).

According to Halliday and Hasan, there are three types of reference, they are personal reference, demonstrative reference, and comparative reference. Personal reference is a reference by means a function in the speech situation through the categories of person. The categories of personal reference include three classes of personal pronoun, possessive determiner (adjective pronoun), and possessive pronoun. Demonstrative reference is a reference by means of location, on scale of proximity. Demonstrative reference expresses through determiners and adverbs. Comparative reference is expressed through adjectives and adverbs and serves to compare items within a text in terms of identity or similarity. Comparative reference is divided into two; "general comparative" and "particular comparative".

Ex: The brave Americans serving our nation today in the Persian Gulf, in Somalia, and wherever else they stand are testament to our resolve. Their cause is American's cause.

If we do not read the first sentence, we do not know the personal pronoun "they" and the possessive adjective "their" are "The brave Americans".

\subsubsection{Substitution}

Substitution is the replacement of one item by another. Halliday and Hasan expound that substitution holds a text together through preventing repetition and creating cohesive grammatical cohesion. The difference between substitution and reference is that substitution lies in the relation between words, whereas reference between meanings. In English, substitute has function as a noun, as a verb, as a clause. There are three types of substitution; Nominal, Verbal, and Clausal. Nominal substitution is substituting a noun or a nominal group with another noun. Elements of this type are one, ones, and same. Verbal substitution involves substituting a verb or a verbal group with another verb. The verb element used to replace items in this type is do. Clausal substitution is substituting clauses by so or not.

Ex: Everyone seems to think he's guilty. If so, no doubt he'll offer to sign.

Here "so" is used to substitute for "he is guilty".

\subsubsection{Ellipsis}


Ellipsis is the omission of a word or a part of the sentence. It is similar to substitution because "Ellipsis is simply substitution by zero" (Halliday \& Hasan, 1976). The essential characteristic of ellipsis is something that is present in the selection of underlying (systematic) option that omitted in the structure. There are three types of ellipsis; Nominal ellipsis, Verbal ellipsis, and Clausal ellipsis. Nominal ellipsis means the ellipsis within the nominal group or the common noun that may be omitted and the function of head taken on by one of other elements. Verbal ellipsis is an elliptical verbal group presupposes one or more words from a previous verbal group. Clausal ellipsis occurs when the clause is omitted.

Ex: For many Americans, this marked the first time they (1) had come face to face, or (2) had allowed themselves to come face to face.

Here "this marked the first time they" is used for both (1) and (2) though it does not occur in (2).

\subsubsection{Conjunctions}

Conjunction is rather different in nature from the other cohesive relation. Conjunctive elements are cohesive not in themselves but indirectly, by virtue of their specific meanings; they are nor primarily devices for reaching out into the preceding (or following) text, but they express certain meaning which presuppose the presence of other components in the discourse. Conjunctions are divided into four types, namely additive, adversative, causal, and temporal. Additive conjunctions connect units that share semantic similarity. Examples of additive conjunctions are and, likewise, furthermore, in addition, etc. Adversative conjunctions are used to express contrasting results or opinions. This type of conjunction is expressed by words such as, but, however, in contrast, whereas, etc. Causal conjunctions introduce results, reasons, or purposes. They are characterized by the use of items such as, so, thus, therefore, because, etc. Temporal conjunctions express the time order of events such as, finally, then, soon, at the same time, etc.

Ex: Democrats were concerned that last year's bruising partisan battles over health care and the budget could hurt their chances in the midterm elections.

In this example, "and" is used to connect the two clauses of one sentence.

\section{Method}

ISSN 2455-6378

As the objectives of the research, descriptive method is used to analyse the frequency and the ways grammatical cohesion are utilized in Vietnamese and English political discourse. The linguistic data are ten Vietnamese editorials and ten English editorials.

\section{Findings and discussion}

In this part, the frequency and the ways grammatical cohesion employed in Vietnamese and English editorials are analysed.

\subsection{Reference}

Figure 1: The use of reference in Vietnamese and English editorials

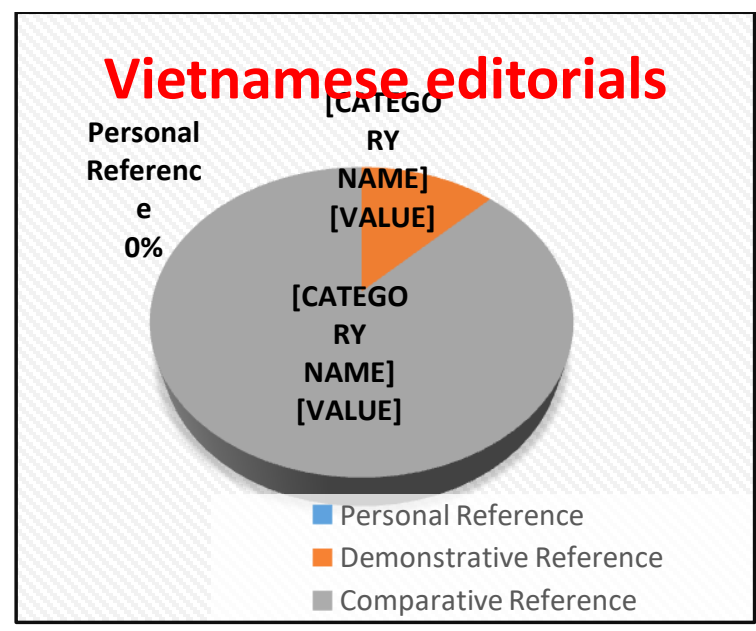

\section{English editorials}

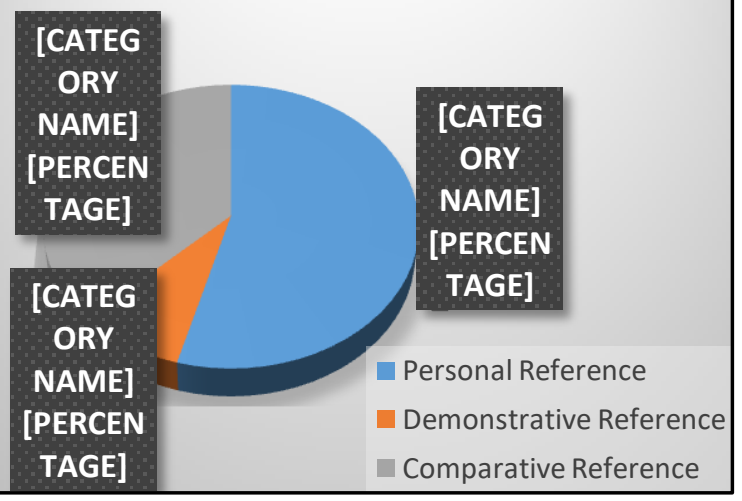

In Vietnamese editorials, the predominant reference is comparative one with $87,5 \%$. The demonstrative reference occupies the second highest frequency with $12,5 \%$. Remarkably, no personal reference is employed in the ten editorials because the percentage of this type is zero whereas it is the most frequently used in English editorials with the percentage of $54,3 \%$. Comparative reference accounts for $37,1 \%$ and the last item with a fairly low percentage is demonstrative with only $8,6 \%$. 
This reveals that reference devices are more regularly employed in English editorials than in Vietnamese ones. Normally, in Vietnamese editorials, pronouns "he", "she" or "they" are not used to substitute for politicians such as "Prime minister", "Deputy prime minister" or “ Minister". For the first time mentioned, the tittle and full name is used (eg: Prime minister Nguyen Xuan Phuc), from the second time, "The prime minister" can be used for the "Prime minister Nguyen Xuan Phuc".

\subsection{Substitution}

Figure 2: The use of substitution in Vietnamese and English editorials

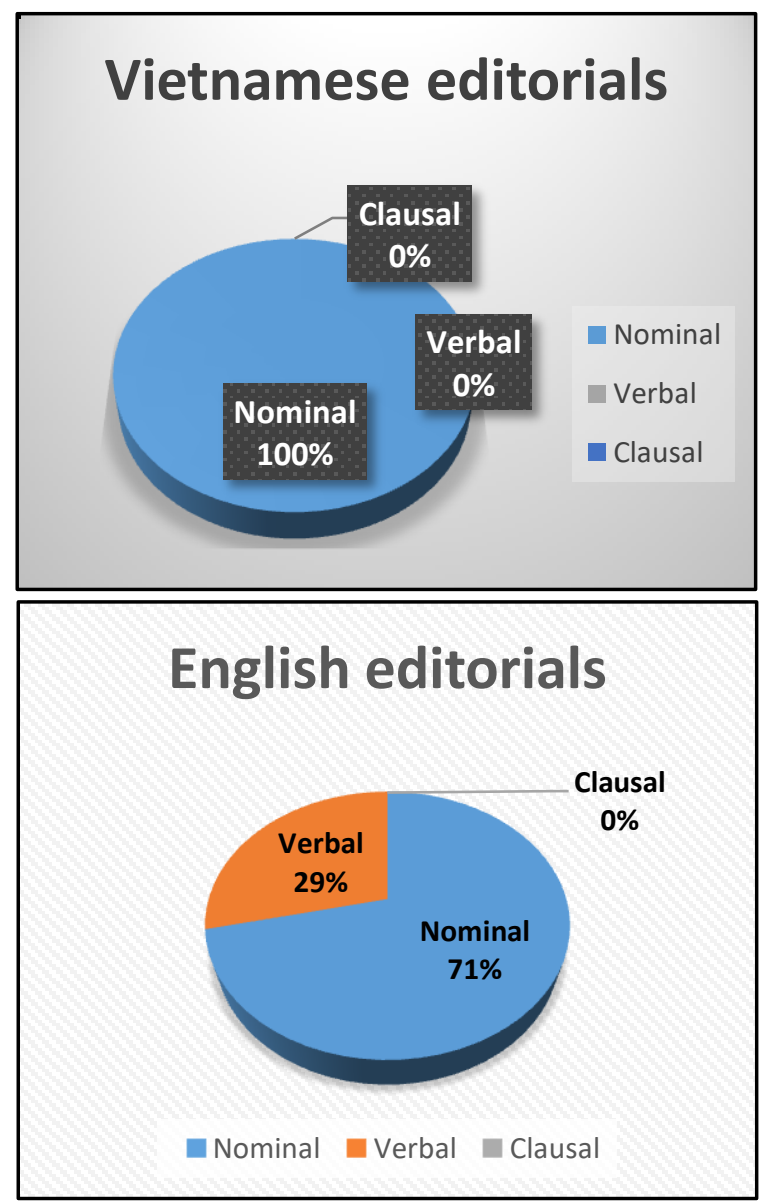

The charts above indicate that nominal substitution is the only one used in the ten Vietnamese editorials. It means that $0 \%$ is the percentage of verbal and clausal substitutions. Similarly, clausal substitution accounts for $0 \%$ in English editorials. Nominal is also employed at the highest frequency with the percentage of $71,4 \%$, verbal substitution is less frequently employed than nominal substitution in
English editorials with $28,6 \%$. It is noticeable that the disparity among the devices is really remarkable, and they are not equally used in both Vietnamese and English editorials.

\subsection{Ellipsis}

Figure 3: The use of ellipsis in Vietnamese and English editorials
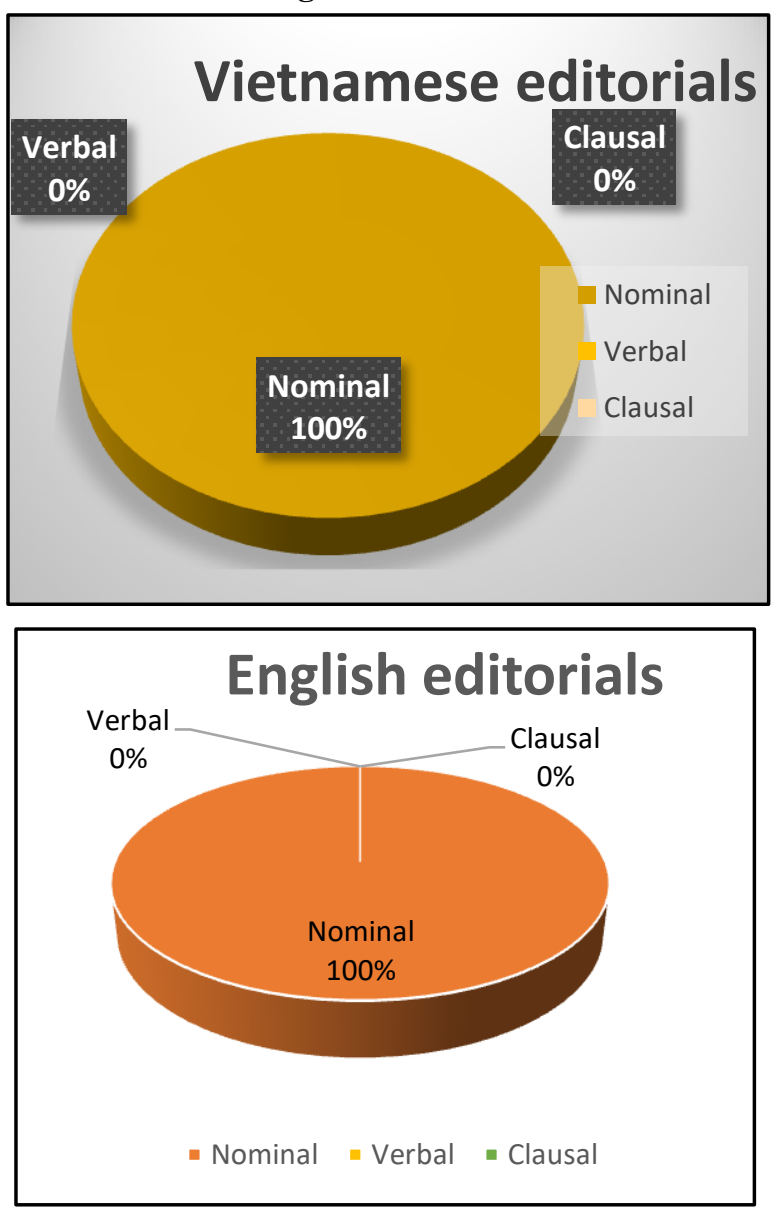

The records above show a really confusing result, because nominal ellipsis is the only one used in both Vietnamese and English editorials. Surprisingly, verbal and clausal ellipses do not occur in the editorials of these two languages. This unbalanced use of these ellipsis devices should be noted significantly. 


\subsection{Conjunction}

Figure 4: The use of conjunction in Vietnamese and English editorials
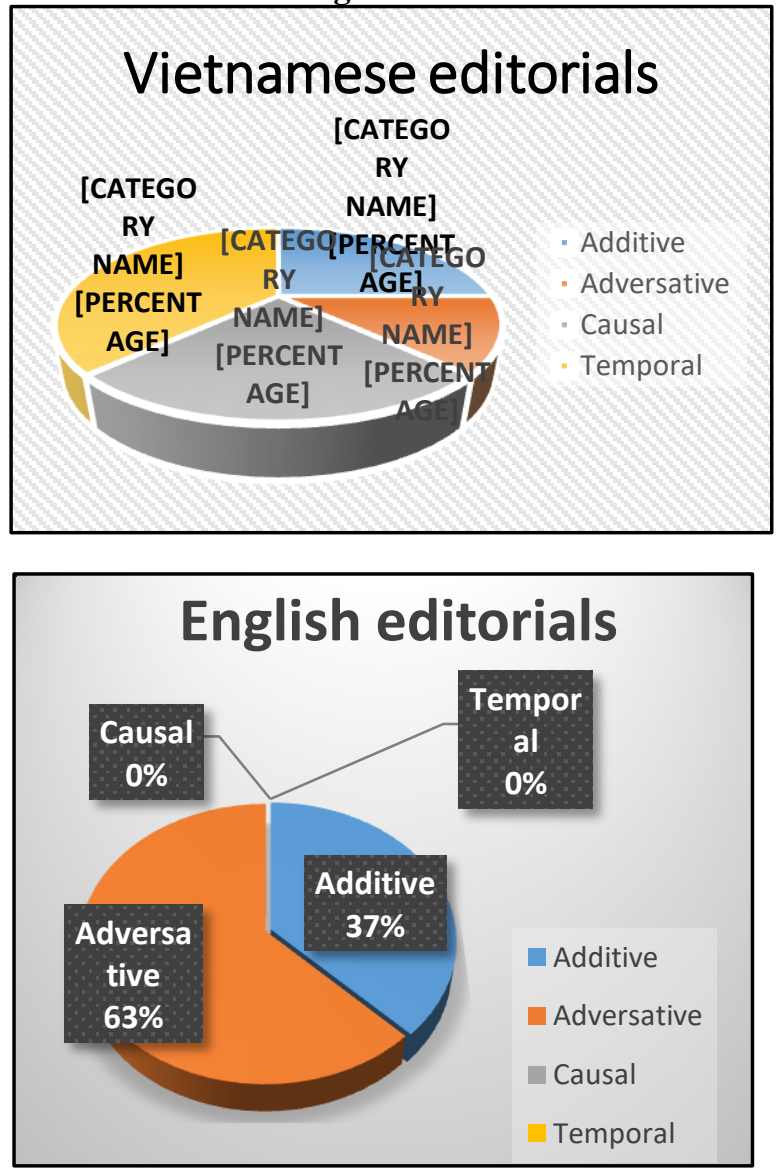

As can be seen from the charts above, all of the four types of conjunction are employed in Vietnamese editorials. The disparity among these four are not really considerable. Specifically, temporal conjunction is the most frequently used with the percentage of $37,5 \%$. What is interesting in this data is that causal and additive conjunctions account for equal percentage $(25 \%)$. The last tendency with minimum frequency is adversative conjunction with the percentage of $12,5 \%$. What is interesting in the data is that only additive and adversative conjunctions occur in English editorials with the percentages are $37,5 \%$ and $62,5 \%$. Noticeably, $0 \%$ is the percentage of clausal conjunction and temporal conjunction. It should be noted that causal and

\section{ISSN 2455-6378}

temporal conjunctions do not occur in English editorials whereas they occur quite frequently in Vietnamese editorials.

\section{Conclusion}

The article has examined the types, roles and frequency of grammatical cohesion in Vietnamese editorials compared with English editorials. All four types of grammatical cohesion including conference, substitution, ellipsis and conjunction are employed. Nevertheless, the disparity of frequency among these devices is remarkable. Noticeably, no personal reference, verbal and clausal substitutions, verbal and clausal ellipses can be found in Vietnamese editorials. On the contrary, nominal substitution and nominal ellipsis account for the maximum frequency with the percentage of $100 \%$. Similarly, clausal substitution, verbal and clausal ellipses, verbal and clausal conjunctions are not utilized in English editorials. Nominal ellipsis is the only device that occupies $100 \%$ of frequency. From all the findings and discussion above, it can be concluded that reference devices are the mostly used with diversification whereas ellipsis devices are employed with an unbalanced frequency in both Vietnamese and English editorials.

\section{Reference}

[1] Bussmann, Hadumod. 1998. Routledge Dictionary of Language and Linguistics. New York: Routledge.

[2] Chilton and Schäffner. 1997. Discourse and Politics Paul Chilton \& Christina Schäffner. SAGE knowlwdge

[3] Halliday, M.A.K and Ruqaiya Hasan. 1976. Cohesion in English. England: Longman. Halliday, M.A.K 1985. An Introduction to Functional Grammar. Britain: Edward Arnold.

[4] Nordquist. 2020. Understanding the Use of Language through Discourse Analysis. ThoughtCo.

[5] Stubbs, M. (1983). Discourse Analysis: The Sociolinguistic Analysis of Natural Language. Chicago, IL: The University of Chicago Press.

[6] Van Dijk, A. Teun. 1997. Discourse as Structure and Process. London. SAGE Publications Ltd. 